\title{
Investigation of Chip Formation in Milling Titanium Alloy
}

\author{
Kamaruddin KAMDANI, Erween Abd. RAHIM, Fitri ABDULLAH, S. THAMIZHMANII \\ Faculty of Mechanical and Manufacturing Engineering, Universiti Tun Hussein Onn Malaysia, \\ 86400 Johor, Malaysia, kmarudin@uthm.edu.my
}

\begin{abstract}
:
In the present work, coated and uncoated carbide tools were used for milling Ti-6Al-4V ASTM B348 under wet cutting condition. The cutting speeds selected for the experiment were 80,120 , and $160 \mathrm{~m} / \mathrm{min}$ with the feed are at $0.1 \mathrm{~mm} /$ tooth. The depths of cut applied were 1.0 and $2.0 \mathrm{~mm}$. From chip cross section and microstructure investigation using optical microscope and scanning electron microscopy (SEM), at the highest cutting speed and lowest depth of cut, the smallest value of chip fluctuation factor can be attained. At this condition the chips are stable with lower vibration. A transition from aperiodic to periodic saw-tooth chip formation occurring with increases in depth of cut and cutting speed. The chip micrograph shows the reduction in secondary deformation zone thickness induced by the coated insert cutting is evidence of reduced friction between the tool rake and the chip. The crack which determines the serrated chip during cutting operation, always occurs in the primary shear zone on the tool tip side.
\end{abstract}

Keywords: Milling, Titanium alloy, Chip formation, Ti-6Al-4V

\section{Introduction}

Titanium and its alloys are lustrous silver metal, has superior strength yet lightweight, good corrosion resistant and capable of being fabricated into a variety of parts and extensively used in aerospace because of their excellent combination of hi-specific strength (strength-to-weight ratio) which is maintained at elevated temperature, their fracture resistant characteristics, and their exceptional resistance to corrosion. Like stainless steel, the low thermal conductivity of titanium reduce dissipation of heat within the work piece itself, thus requiring proper application of coolants [1]. Wang et al. [2] reported that when machining $\mathrm{Ti}-6 \mathrm{Al}-4 \mathrm{~V}$, conventional tools wear rapidly, because the poor thermal conductivity of titanium alloys. Ezugwu et al. [3] stated that success in the machining of titanium and its alloys depends largely on the overcoming of the principal problems associated with the inherent properties of these materials; high cutting temperature, high cutting pressures and chatter. According to Amin [4], milling titanium is a more difficult operation than turning because chips tend to adhere to the teeth during that portion of the revolution that each tooth does not cut which can be alleviated by employing climb milling. When milling titanium alloys using carbide tools, chipping and flaking of the cutting edge are found to be the main cause of tool failure which caused by high cutting temperature, small chip tool contact length and dynamic nature of the normal stresses acting on the tool during machining.

Varieties of chips are normally formed during machining. The nature of the chip formation process is extremely complicated. The exact mechanism or combinations of mechanisms for chip formation depend upon the metallurgical aspects of the tool workpiece system and the cutting process parameters. The preceding chip types were first classified by Ernst in the late 1930s [5]. Since then, the available metals used in machining, cutting tool materials and cutting speeds have all increased, and fourth main type has been identified as continuous chip, discontinuous chip, continuous chip with built up edges and serrated chip [6]. During cutting Ti-6Al-4V at low cutting speed, crack propagates toward to tool tip, which tends to produce a discontinuous chip and at high cutting speed, serrated chip segment formed and no crack occurs in the tool tip side due to the high temperature on the tool face side, and thermal softening effect [7]. Periodic saw-tooth chips are produced when saw-tooth chip formation is suppressed and a continuous type chip forms. But when machining at high cutting speeds, failure occurs through ductile fracture indicate degree of thermal softening within the primary shear zone [8].

Titanium chip formation is a transition from the lowtemperature hexagonal close packed (HCP) structure to the body centered cubic (BCC) structure which localizes the shear strain [8]. According to Cook [9], catastrophic thermoplastic shear results in producing saw-tooth chip. During cutting Ti-6Al-4V at low cutting speed, Hua and Shivpuri [7] declared that crack propagates toward to tool tip which tends to produce a discontinuous chip and Barry et al [8] also stated that periodic saw-tooth chips are produced where saw-tooth chip formation is suppressed and a continuous type chip forms but when machining at high cutting speeds, failure occurs through ductile fracture indicate degree of thermal softening within the primary shear zone. At high cutting speed, serrated chip segment formed and no crack occurs in the tool tip side due to the high temperature on the tool face side, and thermal softening effect [7].

The aim of this work was to investigate chip formation effects when machining titanium alloy Ti-6Al-4V with different cutting parameters in wet condition.

\section{Experimental Set Up}

This paper mainly investigates the cross section and morphology of chip and the hardness of the titanium 
machined surface that occurs when different parameters applied during end milling of Ti-6Al-4V. The tests were performed using uncoated tungsten carbide and coated tungsten carbide inserts under wet cutting condition. The coated material used is titanium aluminium nitride (TiAlN). The machining parameter that applied in the investigation is 1.0 and $2.0 \mathrm{~mm}$ depth of cut with cutting speeds of 80,120 and $160 \mathrm{~m} / \mathrm{min}$. These machining took place at constant feed at $0.1 \mathrm{~mm} /$ tooth. In order to examine the chips cross-section, the chips were mounted in epoxy resin molds, ground, polished and subsequently etched for about $10 \mathrm{sec}$ in picral etchant. The specimens were then photographed and examined using optical microscope and toolmaker's microscope.

\section{Results and Discussions}

\subsection{Chip Side Cross Sectional Analysis}

Tables 1 and 2 show that chips produced during machining at cutting speed $160 \mathrm{~m} / \mathrm{min}$ and depth of cut 1.0 and $2.0 \mathrm{~mm}$ give the lowest value of chip fluctuation factor. It indicates that in this condition the chips are more stable with lower vibration. The value of chip fluctuation factor will decrease when the cutting speed is increased. When the depth of cut increased to $2.0 \mathrm{~mm}$, the chip fluctuation factor values are larger compare to the values at $1.0 \mathrm{~mm}$ depth of cut. This result is same when compared uncoated cutting tool with coated cutting tool.

From Figures 1 and 2, the conclusion that can be drawn is, at the highest cutting speed $160 \mathrm{~m} / \mathrm{min}$ and lowest depth of cut $1.0 \mathrm{~mm}$, the smallest value of chip fluctuation factor can be attained. The highest cutting speed and lowest depth of cut giving the smallest value of chip fluctuation factor and shows in this condition the chips are more stable with lower vibration.

The result also it indicates that chip fluctuation factor for coated cutting tool is lower when compared to chip fluctuation factor for uncoated cutting tool in all condition parameters is applied. This mean, the chips are more stable with lower vibration when machining using coated cutting tool.

Table 1: Comparison of Chip Fluctuation Factors uncoated Cutting Tool.

\begin{tabular}{|c|c|c|c|}
\cline { 2 - 4 } \multicolumn{1}{c|}{} & \multicolumn{3}{c|}{ Average Chip Fluctuation Factor $(\Delta \mathbf{h} / \mathbf{h})$} \\
\hline $\begin{array}{c}\text { Depth of } \\
\text { cut }(\mathbf{m m})\end{array}$ & $\mathbf{8 0} \mathbf{~} / \mathbf{m i n}$ & $\mathbf{1 2 0} \mathbf{~} / \mathbf{m i n}$ & $\mathbf{1 6 0} \mathbf{~} / \mathbf{m i n}$ \\
\hline 1.0 & 0.4452 & 0.4123 & 0.3575 \\
\hline 2.0 & 0.4694 & 0.4231 & 0.3751 \\
\hline
\end{tabular}

Table 2: Comparison of Chip Fluctuation Factors for Coated Cutting Tool.

\begin{tabular}{|c|c|c|c|}
\cline { 2 - 4 } \multicolumn{1}{c|}{} & \multicolumn{3}{c|}{ Average Chip Fluctuation Factor $(\Delta \mathbf{h} / \mathbf{h})$} \\
\hline $\begin{array}{c}\text { Depth of } \\
\text { cut }(\mathbf{m m})\end{array}$ & $\mathbf{8 0} \mathbf{~} / \mathbf{m i n}$ & $\mathbf{1 2 0} \mathbf{~} / \mathbf{m i n}$ & $\mathbf{1 6 0} \mathbf{~} / \mathbf{m i n}$ \\
\hline 1.0 & 0.4398 & 0.3770 & 0.3396 \\
\hline 2.0 & 0.4307 & 0.3926 & 0.3744 \\
\hline
\end{tabular}

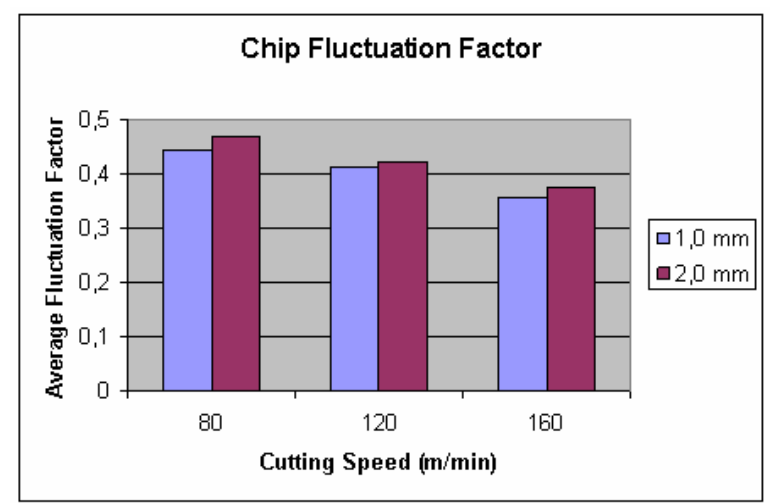

Figure1: Comparison of Chip Fluctuation Factors for Uncoated Cutting Tool.

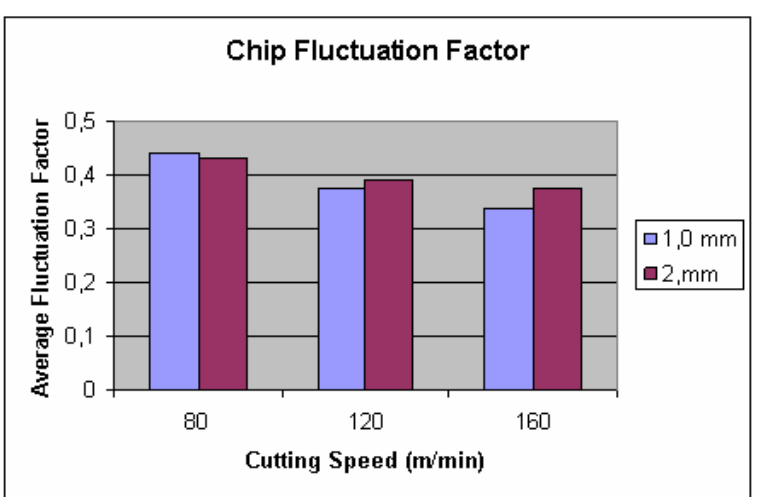

Figure 2: Comparison of Chip Fluctuation Factors for Coated Cutting Tool.

\subsection{Chip Morphology}

Figure 3 shows that the chips produced with the lower depth of cut $1.0 \mathrm{~mm}$, performs aperiodic saw-tooth chips. When the depth of cut is increased to $2.0 \mathrm{~mm}$, periodic saw-tooth chips are formed. The large saw teeth were produced due the presence of chatter since contact length of chip to the tool are high.

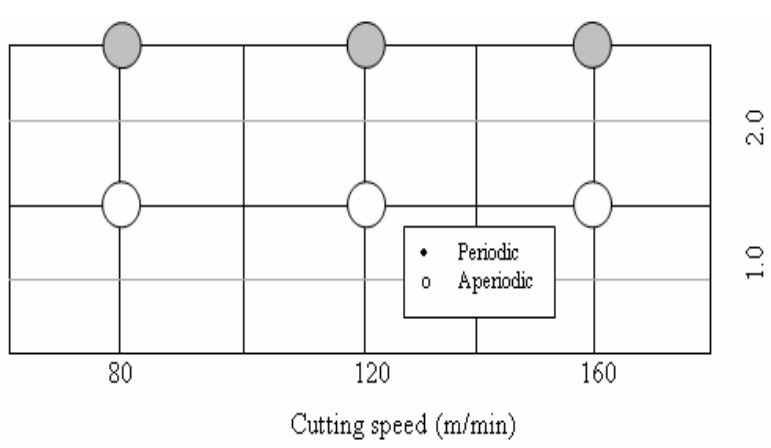

Figure 3: Chip morphology as a Function of Cutting Speed and Depth of Cut.

Figure 4 shows the microscopic structure of the chip samples for uncoated and coated cutting tool cutting using same parameters. One of the most distinguishable differences between the two chip samples is the significantly reduced secondary deformation zone (SDZ) thickness from coated cutting tool cutting. Reduced secondary deformation zone thickness results from the 
lowered tool-chip interface temperature, which makes the chip less plastic, and from the reduced frictional force, which is due to less adhesion between the tool and chip. Therefore, the reduction in SDZ thickness induced by the coated cutting tool cutting is evidence of reduced friction between the tool rake and the chip.
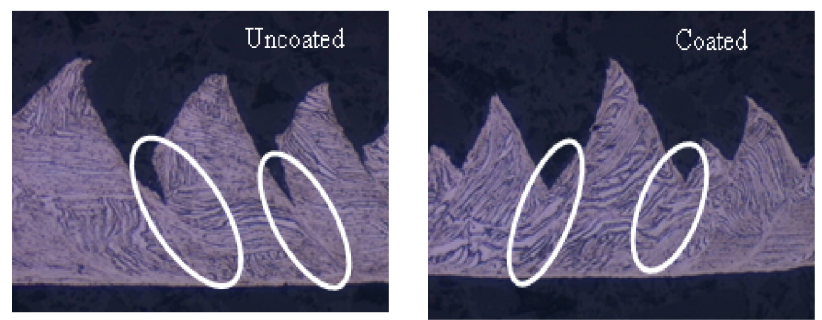

Figure 4: Comparison between Chip Sample for Uncoated and Coated Cutting Tool at same cutting parameters.

From the experimental result, serrated chip also called the shear localized chip segment as shown in Figure 5 always obtained in all machining parameter, and the chip shape and size are different at different cutting speed. The crack, which determines the serrated chip during cutting operation, always occurs in the primary shear zone on the tool tip side. This is the region where maximum principal stress and shear stress locate. Shear stress in the shear plane and tensile stress facilitate the initiation of crack.

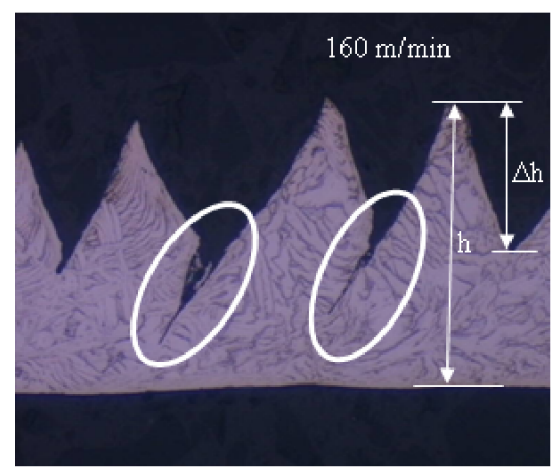

Figure 5: Shear Localization is observed Along Primary Shear Plane in Chip Samples.

\subsection{Discussion}

From the overall observation, the chip at the high cutting speed $160 \mathrm{~m} / \mathrm{min}$ and low depth of cut $1.0 \mathrm{~mm}$ are stable with low vibration because it gives the least chip fluctuation factor value. The chips produced with the lower depth of cut $1.0 \mathrm{~mm}$, performs aperiodic sawtooth chips. When the depth of cut is increased, periodic saw-tooth chips are formed. The large saw teeth were produced due the presence of chatter since contact length of chip to the tool are high. During machining titanium, formed segmented chips were extending across the width of the chip where the structure is aperiodic and periodic in cross-section [8].Friction between the tool and the chip in metal cutting can influence primary deformation and change the shear angle. It also causes secondary deformation in the change of grain structure, a layer where the lines of maximum grain elongation are curved.
Therefore, the chip micrograph can indicate the level of frictional deformation. Reduced secondary deformation zone thickness results from the lowered tool-chip interface temperature, which makes the chip less plastic, and from the reduced frictional force, which is due to less adhesion between the tool and chip [10].

Serrated chip is commonly observed in machining of titanium alloy in all speed ranges and chip morphology under different cutting speed is different. The serrated chip produced in cutting titanium alloys is usually thought to be predominantly due to flow localization in the cutting process and thermal softening in the primary deformation zone. The greater the cutting speed, the higher will become the temperature in primary deformation zone. When the temperature softening effect in the primary deformation zone is stronger than the strain hardening effect, the chip becomes serrated [11].

The use of high depth of cut combined with high cutting speed and feed rate could cause rapid chipping at the cutting edge which leads to catastrophic failure of the inserts [12]. A higher cutting speed also results in rapid cratering and/or plastic deformation of the cutting edge. This is due to the temperature generated, which tends to be concentrated at the cutting edge closer to the nose of the inserts [11]. The heat affected zone is very small when cutting titanium alloys. The smaller heat affected area produced is as a result of the shorter chip/tool contact length [13].

Coatings typically reduce the coefficient of friction between the cutting tool and the chip, and therefore perform better at a lower temperature than uncoated inserts under similar cutting conditions [12]. In machining of Ti-6Al-4V, the use of the proper coating structure can contribute to substantial reduction of the friction action between the rake and the chip, and result in a decrease in heat generation and lower the tool-chip interface temperature. Therefore, it controls heat transfer into the tool body. The thermal conductivity of the coating material significantly influences both temperature magnitude and the distribution in the cutting tool. Increasing the thermal conductivity of the coating layer is helpful for reducing the magnitude of temperature on the tool rake face.

In addition, the high conductivity of the coating increases the distance of the maximum temperature on the rake face from the tool tip. The longer contact length between chip segment and tool rake face, the more space for the heat generated inside the chips during the cutting cycle to conduct to another part of tool environment, reducing the accumulated heat around tool tip, and hence, decreasing the temperature on the tool rake face near tool tip [11].

\section{Conclusions}

The work complete can be summarized as following:

i. During machining, the chips are more stable with lower vibration when using coated cutting tool at high cutting speed, $160 \mathrm{~m} / \mathrm{min}$ and lowest depth of cut, $1.0 \mathrm{~m} / \mathrm{min}$, where the height of the saw teeth is decreasing. 
ii. Increasing values of depth of cut from $1.0 \mathrm{~mm}$ to $2.0 \mathrm{~mm}$, results transition of aperiodic to periodic saw-tooth chip formation due to presence of chatter.

iii. The reduction in secondary deformation zone (SDZ) thickness induced by the coated cutting tool cutting is evidence of reduced friction between the tool rake and the chip.

iv. Serrated chip also called the shear localized chip segment always obtained in all machining parameter, and the chip shape and size are different at different cutting speed. The crack, which determines the serrated chip during cutting operation, always occurs in the primary shear zone on the tool tip side. This is the region where maximum principal stress and shear stress locate. Shear stress in the shear plane and tensile stress facilitate the initiation of crack.

\section{Acknowledgement}

This research work has been funded by Ministry of Science, Technology and Innovation, Malaysia and Research and Innovation Center, University Tun Hussein Onn Malaysia.

\section{References}

[1] Shane, Y. H, Irel Markus and Jeong, W.C, 2001, New Cooling Approach and Tool Life Improvement in Cryogenic Machining of Titanium Alloy Ti-6Al$4 \mathrm{~V}$, International Journal of Machine Tools \& Manufacture, Vol. 41, pp 2245-2260.

[2] Wang, Z.G., Wong, Y.S., M. Rahman, 2005, Highspeed Milling of Titanium Alloys Using Binderless CBN Tools, International Journal of Machine Tools \& Manufacture, Vol. 45, pp. 105-114.

[3] Ezugwu, E.O., Wang, Z.M., 1997, Titanium Alloys and Their Machinability - A Review, Journal of Materials Processing Technology, Vol. 68, pp 262274.

[4] Amin, A.K.M.N., 1982, Investigation of the Mechanism of Chatter Formation during the Metal Cutting Process, Mechanical Engineering Res. Bulletin, Vol. 6, pp 11-18.

[5] Trent, E.M., Wright, P.K., 2000, Metal Cutting, Fourth ed., Woburn, Butterworth-Heinemann, pp (175-225).

[6] Groover, M.P., 2002, Fundamentals of Modern Manufacturing, 2nd.ed., Hoboken, N.J.: John Wiley \& Sons, pp 475-530.

[7] Jiang Hua, Rajiv Shivpuri, 2004, Prediction of Chip Morphology and Segmentation during the Machining of Titanium Alloys, Journal of Materials Processing Technology, Vol. 150, pp 124-133.

[8] Barry, J., Byrne, G., Lennon, D., 2001, Observations on Chip Formation and Acoustic Emission in Machining Ti-6Al-4V Alloy, International Journal of Machine Tools \& Manufacture, Vol. 41, pp 1055-1070.

[9] Cook, N.H., 1953, Chip Formation in Machining Titanium, Proc of the Sym. Mach and Grinding of
Titanium, Watertown Arsenal, Massachusetts, pp 17.

[10] Hong, S.Y., Ding, Y., Jeong, W.C., 2001, Friction and Cutting Forces in Cryogenic Machining of $\mathrm{Ti}-$ 6Al-4V, International Journal of Machine Tools \& Manufacture, Vol. 41, pp 2271-2285.

[11] Jiang Hua, M.S., 2002, Chip Mechanics and Its Influence on Chip Segmentation and Tool Wear, The Ohio State University: Thesis Doctor of Philosophy.

[12] Ghani, J.A., Choudhury, I.A., Masjuki, H.H., 2004, Wear mechanism of TiN coated carbide and uncoated cermets tools at high cutting speed applications, Journal of Materials Processing Technology, Vol. 153-154, pp 1067-1073.

[13] Che-Haron, C.H., Jawaid, A., 2005, The Effect of Machining on Surface Integrity of Titanium Alloy Ti-6\% Al-4\% V, Journal of Materials Processing Technology, Vol. 166, pp 188-192. 